\section{EDUCAÇÃO EM SAÚDE: ALGUMAS REFLEXÕES SOBRE SUA IMPLEMENTAÇÃO PELAS EQUIPES DA ESTRATÉGIA SAÚDE DA FAMÍLIA}

\author{
Education in health: some thoughts on its implementation by \\ the family health strategy teams
}

\section{RESUMO}

Objetivo: Analisar o desenvolvimento da educação em saúde pela equipe multiprofissional da estratégia saúde da família. Métodos: Pesquisa de abordagem qualitativa, com uma coleta de dados por meio de grupo focal realizado com quatro equipes de saúde e um com gestores da saúde do município. Foi utilizada a análise de conteúdo, modalidade temática para analisar o conteúdo dos encontros em grupo. Resultados: Os profissionais reconhecem a importância das atividades de educação em saúde, porém sinalizam algumas fragilidades em atuarem segundo os princípios do Programa devido o foco da assistência ser, ainda, em atendimentos individuais baseados na demanda e o conceito de educação em saúde ainda é limitado. Identificado à realização de algumas atividades de educação em saúde, em cenários diversos e destacam ações intersetoriais. Conclusão: Existe necessidade de investimentos em espaços de reflexão entre os profissionais das equipes e, a educação permanente se mostra como potente ferramenta para possíveis transformações no processo de trabalho em saúde.

Descritores: Estratégia Saúde da Família; Educação em Saúde; Exercício Profissional; Relações Profissional-Paciente.

\section{ABSTRACT}

Objective: The aim of this research was to analyze the development of health education by the ESF professional team. Methods: The methodology was qualitative approach with data collection through focus group conducted with four health teams and with one of the city health managers. Content analysis was used, with thematic modality to analyze the content of group meetings. Results: The results pointed that professionals recognize the importance of health education activities, although they indicate some weaknesses in acting according to the principles of the Program due to the fact that the focus of assistance, still is, an individual assistance based on demand and the concept of health education is still limited. It was identified the performance of some health education activities in various scenarios and intersectoral actions were highlighted. Conclusion: It was concluded that there is need for investment in spaces for reflection among professional teams, and shows how powerful tool for possible changes in the health work process.

Descriptors: Family Health Strategy; Health Education; Professional Practice; Professional-Patient Relations.
Artigo Original

1) Secretaria Municipal de Saúde de Marília - SMS - Marilia (SP) - Brasil

2) Faculdade de Medicina de Marília FAMEMA - Marilia (SP) - Brasil

Este artigo seguiu as normas e formatação estabelecidas pelo $5^{\circ} \mathrm{CIAIQ}$ - Congresso Ibero-Americano em Investigação Qualitativa. 


\section{INTRODUÇÃO}

A organização dos serviços de saúde e a reorientação das práticas e do processo de trabalho em saúde têm sido uma das reflexões constantes na trajetória das políticas de saúde no Brasil. Modelo de atenção à saúde pode ser definido como a forma de organizar os recursos disponíveis para resolução dos problemas de saúde de uma sociedade. No Brasil, foram construídos, acompanhando os momentos vivenciados pela história. Atualmente, a prestação de serviços de saúde no Brasil se estabelece como um modelo de atenção biomédico e, configura-se como um modelo hegemônico ${ }^{(1,2)}$.

Acrescenta-se que, com esse modelo, o foco é o atendimento queixa-conduta, que se resume em dar uma resposta imediata ao problema momentâneo do paciente, ocorre com isso, baixa resolutividade, pouca interferência no prognóstico e na qualidade de vida da pessoa, fazendo com que ela retorne ao serviço outras vezes, gerando outras demandas, o que causa angústia, tanto ao usuário quanto ao profissional de saúde ${ }^{(3)}$.

No entanto, esse modelo de atenção mostrou ter baixa resolutividade e ser excludente, e nas décadas de 70 e 80 houve várias discussões, que culminou em um movimento de universalização do acesso à saúde, no intuito de levar assistência saúde à população em geral ${ }^{(1,2)}$.

Abre-se então um novo capítulo na saúde pública do país, e se constitui como uma das mais importantes conquistas no campo social, a qual apresenta saúde como um direito de todos e dever do Estado, adquirindo caráter universal devendo ser ofertada pelo Sistema Único de Saúde (SUS) $)^{(4)}$.

Com a finalidade de dar ênfase às ações do Sistema Único de Saúde (SUS), garantindo seus princípios, e de provocar mudanças no modelo de atenção à saúde da população, em 1994, foi criado o Programa de Saúde da Família (PSF), atualmente denominado de Estratégia de Saúde da Família (ESF). Esse modelo de atenção, tem seu processo de trabalho centrado na vigilância à saúde, trabalha em um território de abrangência definida, com ênfase no atendimento ao núcleo familiar, com vistas à promoção e recuperação da saúde, além da prevenção dos agravos família ${ }^{(5)}$.

As ações da ESF são realizadas por uma equipe multiprofissional, de forma a alcançar atenção integral aos indivíduos, família e comunidade. Neste contexto, a saúde bucal foi inserida na ESF, em dezembro de 2000, por meio da Portaria 1.444, deixando de ser um atendimento voltado ao escolar e às urgências odontológicas. Em 2004, o Ministério da Saúde desenvolveu as "Diretrizes da Política Nacional de Saúde Bucal”, que traz uma reorientação na sua forma de atuação em todos os níveis de atenção. Aponta-se assim, para a importância de desenvolver ações intersetoriais e expandir os trabalhos da atenção básica para além da concepção de saúde, centrada no atendimento ao doente, com maior aproximação das necessidades de saúde da população ${ }^{(6,7)}$.

Dentre os grandes desafios das equipes, a educação em saúde tem papel de destaque, por ser um espaço com possibilidade de fomentar reflexões, contribuir com mudança de práticas e posturas, que busquem promover a saúde e prevenir a manifestação de doenças. Contudo, têmse diversas formas de desenvolver educação em saúde. O desafio é qual a melhor proposta para estimular as reflexões?

O modelo emergente de educação em saúde pode ser referido como modelo dialógico por ser o diálogo seu instrumento essencial. O objetivo da educação dialógica não é o de informar para saúde, mas um encontro de sujeitos que busquem refletir e transformar saberes existente. A prática educativa e problematizadora visam o desenvolvimento da autonomia e da responsabilidade dos indivíduos no cuidado com a saúde, para que esses se tornem cidadãos ativos no campo político e social, além de obter maior resolutividade das ações e melhor impacto dos indicadores de saúde e de qualidade de vida da população assistida. O usuário dos serviços é reconhecido sujeito portador de um saber, que embora diverso do saber técnico-científico não é deslegitimado pelos serviços ${ }^{(8)}$.

Destarte, a educação em saúde se estabelece como um dos requisitos que visa potencializar ações de prevenção e promoção à saúde na ESF, com a finalidade de suscitar processos de educação e construir conhecimentos em saúde buscando transformar e se apropriar de saberes existentes além de fortalecer a autonomia e cidadania das pessoas no processo saúde-doença com consequente mudança de hábitos, trazendo ações que busquem melhoria na qualidade de $\operatorname{vida}^{(8)}$.

Sendo assim, é importante compreender se as equipes estão desenvolvendo educação em saúde, visando à prevenção e promoção da saúde direcionada à interdisciplinaridade e intersetorialidade. Diante disso, o objetivo da pesquisa é analisar o desenvolvimento da educação em saúde pela equipe multiprofissional da ESF.

\section{MÉTODOS}

Pesquisa pautada na abordagem qualitativa. Os dados foram coletados por meio de grupos focais no período de setembro a dezembro de 2015. O grupo focal consiste em um tipo de entrevista em grupo, com questões norteadoras a serem exploradas e discutidas pelos participantes do grupo. As entrevistas foram gravadas e transcritas na íntegra ${ }^{(9,10)}$. 
Os grupos focais foram realizados em quatro equipes da Estratégia de Saúde do Município de Marília, sendo uma de cada região da cidade (Oeste, Leste, Sul e norte; denominadas respectivamente de E1, E2, E3 e E4), e um outro grupo com participação de apoiadores da atenção básica da Secretaria Municipal de Saúde de Marília que foi denominada equipe de apoio (EA).

Os profissionais das equipes que participaram foram: médico, cirurgião-dentista, enfermeira, auxiliar de enfermagem, auxiliar de escrita, agentes comunitários e auxiliar de saúde bucal. O grupo de apoiadoras foi constituído por duas dentistas e duas enfermeiras ${ }^{(11)}$.

Para a análise dos dados a opção foi a análise de conteúdo temática por ser uma técnica usada para descrever e interpretar textos seguindo as fases seqüenciais propostas por Minayo: pré-analise, exploração do material e o tratamento dos resultados. Esse tipo de análise é importante na interpretação das mensagens, que podem assim compreender os seus significados em um grau que vai além de uma leitura comum, por uma abordagem metodológica com atributos e possibilidades própria ${ }^{(12)}$.

A pesquisa foi realizada após aprovação do Comitê de Ética em Pesquisa com seres humanos sob protocolo ${ }^{\circ}$ 674/2014.

Após a análise dos dados, foram identificadas duas temáticas que foram: Reflexões sobre as possibilidades da proposta da ESF e Avanços e desafios na construção da educação em saúde.

\section{RESULTADOS E DISCUSSÃO}

\section{Reflexões sobre as possibilidades da proposta da ESF}

Em relação ao modelo de atenção à saúde, obtivemos que os profissionais das equipes identificam e refletem sobre a necessidade de realizar a transformação para um modelo que amplie o cuidado, no entanto, sinalizam que o foco ainda está na doença e não no cuidado a pessoa de forma integral:

“(...) a gente está há muito tempo tentando fazer essa transição de modelo, mas a gente ainda reproduz aquele modelo que é ainda centrado na doença, ainda centrado na redução de danos, e não na prevenção e na educação a gente tem essa dificuldade de atravessar essa ponte. "(EA)

Conforme Silva Júnior e Almeida ${ }^{(2)}$, no Brasil, convivemos com dois modelos de atenção predominantes: o modelo médico hegemônico e o modelo sanitarista onde não trabalham o principio da integralidade em suas ações, pois focam em atendimentos à demandas no estilo queixa conduta, ou em resolver necessidades que não se configuram como demandas. Essa afirmação coaduna com a fala do participante que faz abordagem sobre a dificuldade para o desenvolvimento de um modelo de atenção voltado para a prevenção e educação em saúde. Salienta-se, no entanto, que entre os profissionais já existe o reconhecimento sobre a importância dessa transformação, a qual envolve significativas mudanças na forma de pensar e agir em saúde ${ }^{(2,13)}$.

É importante resgatar que a ESF enfatiza os seguintes aspectos: trabalho em equipe, promoção da saúde por meio de ações educativas, divisão das responsabilidades de saúde entre os serviços de saúde e a população, substituição das práticas de saúde convencionais de assistência por novos processos de trabalho, entre outros. Contudo, as mudanças ainda são pequenas, uma vez que os atores envolvidos no processo mantém no seu imaginário o modelo hospitalocêntrico. Sendo necessário, portanto, mudanças paradigmáticas, envolvendo a forma de pensar e agir em saúde com a necessidade de englobar todo o sistema de saúde nos seus diferentes níveis de complexidade e não apenas a $\operatorname{ESF}^{(14,15)}$.

Outro aspecto identificado no conteúdo das falas, diz respeito aos desafios e amarras que os impedem de avançar no desenvolvimento de ações inovadoras, destacando sentimentos de impotência como representado no seguinte relato:

(...) "a angústia pelo menos minha, como enfermeira, é a questão de a gente não estar mais fazendo saúde da família como deve ser, descaracterizou a questão de saúde da família em (nome da cidade), eu acho que a nossa unidade não é diferente dessas (...), você resolve, tem uma resolutividade rápida entre aspas para o paciente, porém não é rápida, porque se você não olha o paciente, não faz uma escuta ampliada você não consegue ter resolutividade, você resolve o problema dela naquele momento mas amanhã ele vai voltar com uma demanda muito maior do que ele apareceu ontem".(E3)

"então eu sinto um pouco desanimada porque você faz planos, você tem a vontade de fazer, mas você não consegue realizar." (E3)

"estamos só apagando incêndios você começa um grupo, você não consegue finalizar, você não consegue dar atenção devida ao paciente, porque se tem aquele e tem mais umas vinte pessoas te aguardando, você começa a ficar angustiada." (E3)

Além do sentimento de impotência, é fato que diante da situação acima as equipes de saúde conseguem identificar fragilidade nas ações realizadas frente ao desejável e ao possível, pois o atendimento realizado na atenção básica depende do funcionamento de toda a rede de atenção. Sem esse funcionamento, a demanda retorna para a atenção básica, por ser a porta de entrada e o local que conseguem ter acesso. 
Hoje a lógica da ESF se fundamenta em atendimentos individuais com consultas médicas, odontológicas e de enfermagem e tem suas ações baseadas na demanda classificadas em grupo de risco indo na contra mão de uma mudança de modelo de atenção. Tem-se claro, portanto, que apenas com o trabalho da ESF não será possível para modificar o quadro atual; será preciso intervenções em toda a rede de atenção à saúde, bem como nos microprocessos de trabalhos cotidianos de cada profissional ${ }^{(16)}$.

Reforçando sobre as dificuldades de investir em atividades que visam às mudanças de modelo temos as falas a seguir:

“(...) assim antes a gente dispunha de uma questão de números de grupos maiores inclusive porque todo mundo participava do grupo e tinha um que coordenava o grupo e ai com a questão da dengue a gente acabou se perdendo porque assim não da pra otimizar esses grupos; a gente tenta otimizar mais um ou outro". (E3)

"então é uma sobrecarga muito grande em cima de nós... mudança do sistema de informações do SIAL pro ESUS, a questão do cadastro, a questão da dengue, vêm dificultando muito."(E3)

Percebe-se que além de atendimentos cotidianos, as equipes ainda têm que lidar com as demandas espontâneas que chegam pelas situações de epidemias como a da dengue, zikavirus dentre outras que acabam por acarretar aumento significativo de atendimento e sem um planejamento adequado de ações e falta de recursos humanos, acabam gerando uma sobrecarga de trabalho, desmotivação, estresse e o tempo despendido nesses atendimentos fazem com que haja uma diminuição das outras atividades propostas pela estratégia.

Nada obstante, o que se observa na literatura a respeito dessas consultas não agendadas conhecidas como as demandas espontâneas, é que elas fazem parte do dia a dia das equipes de saúde e são de competência da ESF por considerar a saúde da Família como porta de entrada ${ }^{(16)}$.

Para isso, é preciso que haja um planejamento adequado tanto na macro como na micro organização do sistema, visando proporcionar recursos adequados para atender as necessidades.

Além disso, as equipes de Saúde da Família ao assumirem o compromisso de reforma do modelo de atenção à saúde, pela construção do SUS, assumem a responsabilidade pelo cuidado ao usuário e para enfrentar os problemas decorrentes; é preciso buscar modos de atuar sobre as demandas e de se relacionar com serviços especializados e hospitalares, visto que atenção básica e esses serviços trabalham em lógicas diferenciadas ${ }^{(17)}$.
Para dar conta das necessidades das famílias sob sua responsabilidade, buscando cuidar da pessoa na sua integralidade, o número adscrito definido para as equipes atuarem dificulta compreender a singularidade de cada um, como a reflexão a seguir:

"eu acho que as áreas de periferia, deveriam ter um olhar a quantidade de população que a unidade de periferia atende é muito grande, não da pra seguir nenhum protocolo, que o ministério da saúde muitas vezes preconiza porque cada realidade é diferente da outra, (...) como a mesma quantidade de profissionais assim como o NASF o núcleo de apoio a família ele ser um padrão pra todas as unidades então deveria ter um olhar diferente infelizmente não tem, nós profissionais não somos olhados com equidade de jeito nenhum, nem as unidades são olhadas assim".(E3).

Essa fala traz um questionamento importante de que as equipes são organizadas sem considerar as necessidades locais, uma vez que este aspecto é relevante quando se trata de trabalho em terrítório adscrito, o que significa trabalhar com as necessidades de cada população.

\section{Avanços e desafios na construção da educação em saúde}

Os profissionais acreditam que as equipes de saúde não realizam as atividades de educação em saúde por desconhecerem o conceito em si, como é referenciado nas falas abaixo:

“(...) porque eu vejo ainda uma mudança muito incipiente num processo de educação para a população e que eu não acho hoje que tem uma categoria profissional dentro da estratégia que faça educação em saúde eu acho que a gente nem sabe direito o que é isso a gente precisa evoluir mais, eu acho que as equipes incluindo o cirurgião dentista se aproxima um pouco mais e tem alguns insites de educação..." (EA)

"uma das dificuldades é que o profissional de saúde formado que trabalha é conhecer o SUS e o que é educação em saúde; acho que a formação de muitas categorias profissionais estão muito aquém do que chegar em conhecer o que éo SUS, quais são as diretrizes, o que é politica de atenção básica, qual é o papel do profissional de saúde na atenção básica e que dentro de todos esses princípios está a educação em saúde também." (EA)

Trabalhar educação em saúde é um modo de provocar alterações no modo de vida e comportamento da população de uma maneira a atuar na lógica da promoção, a qual deve ser entendida como uma estratégia de produzir saúde, no campo coletivo e individual. Mediante a esse entendimento é relevante que o usuário seja visto como um ser com 
autonomia capaz de produzir o próprio estilo de vida saudável. Com a finalidade de construção da autonomia do sujeito, uma das maneiras é a partir dos processos de educação em saúde ${ }^{(8,18)}$.

Apesar de apontarem dificuldades no entendimento, os profissionais das equipes, sinalizam algumas intervenções preventivas e de promoção presentes em ações de saúde realizadas durante o processo de trabalho seja nas consultas individuais, em visitas domiciliares ou em grupos educativos.

"porque quando falamos em promoção à saúde não vamos tratar só a doença a gente vai cuidar para que essa doença não venha. Assim, a gente cuida dessa população como um todo, verificando como ela vive, tanto psicologicamente como no ambiente onde ela vive”. (E2)

"se o paciente vier para fazer uma prevenção, papanicolau mas eu vejo que ela é uma paciente obesa ou que é tabagista eu não vou fazer só a prevenção eu vou fazer uma educação em saúde não só na parte de saúde sexual e reprodutiva mas também na parte do tabagismo dos riscos que ela corre, ofereço os serviços que tem na unidade, ofereço os grupos que tem na unidade, sempre fazendo educação em saúde com os pacientes. "(E2)

“(...) assim sempre que nasce um bebe, a fono, a gente sempre leva a fono com as alunas na casa, hoje mesmo eu levei e assim ela faz orientação sobre amamentação, o que causa, o que a mamadeira causa, o que a chupeta causa na criança..."(E1)

“(...) o grupo de artesanato (...) todos participam ajudam todos os profissionais, a ultima vez foi a dentista que participou(...)que esclareceu muito bem elas, elas tinham muitas duvidas a respeito de tratamento de canal, limpeza de prótese, foi muito bom, muito bom. "(E4)

Com a preocupação de não apenas avaliar a queixa apresentada os fragmentos colocados buscam compreender a saúde da pessoa de forma poder realizar um cuidado mais integral. No entanto, não é possível compreender como essas ações estão sendo realizadas e se está acontecendo uma relação dialógica e, com isso contribuir na compreensão e mudança nas práticas das pessoas assistidas.

Provocar mudanças no comportamento individual, a fim de se obter indivíduos com o domínio das suas vidas, capacita-los a ter controle sobre os determinantes da saúde através de participação em grupos a fim de transformar a realidade social e política é o que traz o conceito da promoção em saúde. Educação em saúde pode ser entendida como uma forma de capacitar a comunidade para melhorar a qualidade de vida e saúde, satisfazer as necessidades da população e modificar o meio ambiente ${ }^{(19)}$. Assim entendida a proposta de educação em saúde, percebe-se a necessidade de articular outros setores do município. As equipes destacam também ações intersetoriais na busca de parcerias nas atividades de educação em saúde:

"nós também fazemos o trabalho de escovação nas escolas que é um trabalho de procedimento coletivo feito na emei da nossa área"." (...)e também o trabalho que é feito na escola de educação em saúde".(E2)

“(...) um grupo de atividade física, é de segunda e quarta que funciona são dois professores, um é o professor do NASF e outro professor que é da secretaria de esportes ele vem voluntário, dar um apoio para nós toda segunda". (E1)

“(...) a gente tem aqui na nossa unidade uma parceria que acontece toda quinta feira o grupo de terceira idade e também tem o grupo de artesanato que é composta por senhoras e tem uma voluntaria." (E2)

São muitos os desafios existentes para a saúde pública no Brasil, e como forma de enfrentamento a Política Nacional de Promoção à Saúde traz a intersetorialidade como uma articulação entre diversos setores no que se diz respeito à saúde, na tentativa de se mobilizarem a fim de gerar intervenções que a propicie, para provocar a coresponsabilidade na saúde. Esses setores devem considerar o diálogo e a criação de vínculos na busca de responder às necessidades de saúde da população e, sobretudo com a participação da comunidade nas ações desenvolvidas ${ }^{(20,21)}$.

Como observado nos fragmentos acima, as ações intersetoriais fazem parte do cotidiano nas equipes de saúde e se constituem em uma nova forma de reorganizar o processo de trabalho. Com a importância de associar diferentes saberes, conhecimentos e diversos modos de atuação sobre um determinado bem comum buscam-se na parceria com outras secretarias, entidades organizacionais ou na própria comunidade soluções e enfrentamentos conjuntos para os problemas encontrados na população em busca de maior capacidade de enfatizar acidadania, um maior cuidado consigo com os outros e com a vida, obtendo assim em uma maior resolutividade.

As equipes sinalizam como atividades de saúde eventos para a população como observado nos discursos abaixo:

\footnotetext{
"Todo mês a gente acaba tendo um evento onde a gente reúne a população... Então acaba sendo uma promoção esses eventos acaba sendo assim um momento de descontração não é aquele momento formal que vai estar só diante da enfermeira e do médico, do dentista tratando só de alguma coisa, é um momento bastante informal, $e$ acaba sendo muito gostoso".(E2)

"até assim os eventos que acontecem aqui na unidade acaba sendo de promoção a saúde.”(E1)
}

Uma das estratégias que as equipes realizam constantemente para garantir melhoria da qualidade de 
vida da população são eventos direcionados a população em geral. No entanto, deve - se ter entendimento que para se constituir em uma atividade de educação em saúde; as ações devem provocar mudanças de atitudes comportamentais na população, fortalecer a consciência do individuo sobre si e a sua realidade e não pode ser confundida como apenas uma atividade a mais a ser realizada, ou um ato de encontro entre profissionais e usuários.

Durante as entrevistas podemos observar que as atividades de educação em saúde, na visão dos participantes, estão diretamente relacionadas com a cultura brasileira, que tende a ser passiva, acrítica e de resistências às mudanças:

"Essa cultura que o brasileiro tem de receber, receber, receber e pouco refletir sobre a sua prática, dificuldade de aceitar coisas novas, e ao mesmo tempo querer e propor a querer fazer mudanças de se propor a mudar. eu vejo isso como uma característica porque não é só aqui no municipio, a gente olha assim tantas coisas, agora, por exemplo, a gente ta passando por uma epidemia de dengue não está preparada pra esse tipo de abordagem, que envolve primeiro a questão de mudança interna pra depois ser externa."(EA)

Cultura é um tema pouco estudado na formação dos profissionais de saúde, logo é possível perceber a relutância e o bloqueio que os profissionais sentem em trabalhar o tema, mas, é preciso que o profissional saiba que quando o individuo nasce ele é portador de certos saberes e com o decorrer da vida é adquirido outros e que todo esse saber adquirido e acumulado pelo meio em que se vive é possível de ser modificado a partir de uma adequada orientação e comunicação no sentido de intencionar a uma nova formação de saberes e compreensão de conhecimentos adquiridos. No entanto, é preciso reconhecer que a mudança acontecerá de forma lenta, pois, a cultura brasileira não está preparada nem para educar e nem para ser educado. Essa cultura esta enraizada em pouco refletir sobre a sua prática, com dificuldades de receber o que se propõe a mudar e aceitar o novo. Para se criar novos hábitos é preciso antes de tudo que o profissional considere as práticas populares existentes pelas famílias e que venham a entende-las melhor e aprender a lidar com essas práticas para que possa ajudar a população a compreender a necessidade dessas mudanças para que o processo de conscientização seja efetivo ${ }^{(22)}$.

Cultura é um termo muito complexo e abrangente, inclui valores, símbolos e normas, e pode ser definida como um conjunto de práticas exercidas por determinados membros de um grupo social. A cultura forma as necessidades biológicas humanas. $\mathrm{O}$ homem herda o conhecimento e a experiência adquirida pelas gerações que o precederam, motivando seu comportamento e justificativas de seus atos. O modo cultural pode limitar ou estimular a capacidade do individuo. Contudo, o homem é um ser inteligente e pode utilizar seus conhecimentos e informações recebidas ao seu dispor ${ }^{(22,23)}$.

Como dito anteriormente, a influência cultural é presente e continua sendo muito utilizada pela população na solução de problemas de saúde. Sendo assim, é importante que os profissionais possam visualizar o indivíduo com suas próprias concepções a respeito de sua saúde-doença, se tornando uma exigência olhar para o contexto social e econômico do paciente para se ter uma visão mais abrangente a fim de procurar entender os motivos pelos quais as pessoas buscam alternativas em seu cuidado à saúde. As crenças e culturas do paciente devem ser compreendidas e ao profissional cabe a função de conhecer melhor e acrescentar conhecimentos e comportamentos oriundos de seu saber cientifico, buscar condutas ativas para desmitificar o negativo que possa existir e construir um relacionamento com base na comunicação e no respeito ${ }^{(24)}$.

Em relação ao olhar do paciente, frente ao processo saúde-doença, é observado que eles mantêm uma concepção de saúde medicalizada, o que dificulta intervenções voltadas para a promoção, pois envolve mudanças de hábitos arraigados, conforme segue:

“assim eu preciso emagrecer você não precisa de remédio para emagrecer então é um caminho mais árduo mas o paciente ele não se mostra convencido, ele se mostra com aquela visão da medicina tradicionalista ainda, eu preciso de remédio. Sem o remédio como eu vou ficar, como eu vou dormir a noite então ele ainda tem essa visão e essa visão pelo menos é uma das minhas dificuldades".(E1)

“(...) porque o paciente pensa assim eu vou lá na Dra. e de lá eu não saio sem remédio então ainda o paciente tem essa visão e é muito difícil nós como profissionais quebrar isso e falar não você não precisa de remédio o que você precisa é isso, isso, isso. "(E1)

De acordo com as falas acima fica evidente que o usuário ao procurar o sistema de saúde chega com suas próprias concepções e uma série de crenças a respeito do processo saúde-doença e cura que dificulta as mudanças de comportamentos. Em suma, é a cultura que determina essas particularidades.

Desse modo, é importante que o profissional de saúde tenha um entendimento e procure se contextualizar com o cultural e social desse paciente e acrescentar a esse saber popular conhecimentos e saberes científicos, que resulte em mudanças nas atitudes, posturas e condutas adotadas na relação profissional-paciente, e ao exercer práticas preventivas durante seu processo de trabalho tem que se tomar cuidado porque ela não irá apenas abordar a doença, mas deverá provocar mudança de hábitos e comportamentos. 
Como já foi dito a educação em saúde deve estar intimamente ligada à vida e saúde da população. Para tanto é preciso saber identificar as necessidades de saúde a fim de serem trabalhadas para que ocorram mudanças de atitudes e práticas além de criar autonomia para melhoria de qualidade de vida. Sendo um processo de aprendizagem ativo, a educação em saúde pode causar conflitos no cidadão, pois tende provocar mudanças em seu modo de viver e atitudes, bem como em sua cultura e crenças ${ }^{(25)}$.

Em relação à assiduidade do cidadão a atividade de educação em saúde pode-se observar por meio dos relatos abaixo que a procura acontece devido a interesses próprios:

“(...) no caso do grupo de resultados de exames eles vêm porque têm curiosidade de saber o resultado do exame eu tenho um propósito, eles vêm pela troca, porque se fosse fazer de uma maneira aleatória, olha gente hoje vai ter orientação alimentar no posto assim toda terça terá o grupo de orientação alimentar com a participação de alguns profissionais eu acho que iria dar pouca adesão”. (E1)

“(...) sempre tem que ter um chamativo (...) sorteio de brindes, café da tarde, porque dai a adesão.(E3)

Fica evidente que o usuário busca o sistema de saúde com a concepção de resolução do seu problema ou que seja algo de seu interesse, sendo assim sua intenção e desejo é participar apenas de ações que tenham respostas para as queixas que o levou à procura do serviço de saúde. A relação de troca também é estabelecida com frequência nos serviços de saúde para adesão às ações de saúde, sendo que o usuário se desloca ao serviço de saúde em busca satisfazer uma necessidade que não é a de adquirir conhecimento com vistas à autonomia e à melhoria das condições de saúde.

Frente a essa situação, o profissional da saúde parece ficar com a sensação de ter cumprido com sua missão, mas com a compreensão de que essa forma de agir não contribui para a efetividade das ações de educação em saúde. Depreende-se, no entanto, que essa situação merece estudos mais aprofundados, visando evidênciar o verdadeiro sentido dessa estratégia na promoção da saúde.

A esse respeito, tem se constatado que os processos educativos construídos pelos profissionais de saúde devem levar em consideração as razões, os interesses e os saberes da população para que o conteúdo seja significativo para o usuário, de forma a despertar o interesse pelas ações e não o saturamento de informações afim de que o trabalho da educação em saúde não venha a perder o valor ${ }^{(26)}$.

Para realizar cuidado em saúde na população, o serviço oferecido deve estar em condições exigidas pelo paciente e não nas condições que o serviço apresenta, sendo de fundamental importância colocar-se à disposição das necessidades do outro, em uma abordagem de seus interesses, um processo de trabalho pautado nas necessidades de saúde da população, pois, assim o processo de trabalho irá de encontro com essas necessidades por meio de uso de práticas de ação como vínculo e acolhimento e uma maior participação do usuário frente às atividades preconizadas pelas equipes de saúde ${ }^{(27)}$.

Um dos problemas detectados para as ações de educação em saúde citados é a pouca/falta de adesão da comunidade as atividades:

“(...) dificuldade que a gente tem é uma não adesão da população (...) a gente não consegue um numero que a gente gostaria pra estar fazendo a educação em saúde com essa população”.(E2)

“(...) a gente acaba tendo essa dificuldade porque elas não querem aderir, acordam tarde, muitas trabalham meche com, tem envolvimento com pessoas do trafico, ou o companheiro mexe com a questão do trafico então muitas ficam a noite inteira acordada, e dormem durante o dia, e outras trabalham e não tem como participar do grupo."(E3)

Para que ocorra sucesso nas atividades de educação em saúde, a motivação e a cooperação consciente do paciente são fatores essenciais para que se obtenha êxito. Observase com as falas acima que a comunidade não considera as ações de educação em saúde importantes. A pergunta que se faz é quais são os motivos dessa não adesão da população? Diante disso, é preciso que seja feita uma discussão a respeito de maneiras efetivas para que sejam construídos modos de alcançar essa população para que aconteça essa valorização do paciente frente a essas atividades.

Em um estudo realizado sobre os motivos dessa não adesão da população foi encontrado desinteresse da população, incompatibilidade com os desejos e possibilidades da comunidade, dificuldades em exercer a cidadania e ênfase no modelo biomédico ${ }^{(28)}$.

A participação social reconhece o direito da população a participar nas decisões que afetam sua vida cotidiana e se promove como espaço democrático para o controle social das instituições, sendo vista como instrumento de aprimoramento da gestão de políticas sociais, visando garantir a efetiva proteção social contra riscos e vulnerabilidades, assim como a vigência dos direitos sociais $^{(29)}$.

Em suma, para melhorar a adesão do usuário às atividades educativas proposta pelas equipes e assim maior efetividade das ações de educação em saúde é preciso ir além da construção de vínculos entre paciente e profissional de saúde. É necessário que haja uma criatividade pelo profissional de saúde, como o reconhecimento das 
necessidades de saúde da população, maior divulgação, melhor comunicação e o uso de metodologias ativas de aprendizagem com apreço à liberdade de expressão.

\section{CONSIDERAÇÕES FINAIS}

Considerando que o objetivo da pesquisa foi analisar o desenvolvimento da educação em saúde pela equipe multiprofissional da ESF, identificamos que as equipes reconhecem a importância das atividades de educação em saúde. Contudo, o conceito que possuem a respeito do tema torna essas ações limitadas e, quando têm uma compreensão melhor, apontam dificuldades para incluir a educação em saúde na prática cotidiana dos serviços. No entanto, os profissionais referem algumas ações de educação em saúde que são realizadas em alguns cenários, e destaca também ações intersetoriais presente nas atividades.

A cultura das pessoas tem influências importantes no desenvolvimento das ações relacionadas às atividades de educação em saúde e, a compreensão, por parte dos profissionais, desse contexto das pessoas assistidas, contribui diretamente na efetivação desse processo.

Em relação ao processo saúde-doença os pacientes ainda possuem um olhar medicalizado o que acaba por dificultar as intervenções de prevenção a doenças e de promoção à saúde. Sugere-se, portanto, que os profissionais ao desenvolverem ações de educação em saúde leve em consideração os interesses e saberes da população e tenham o cuidado em saúde pautado nas necessidades de saúde da população, a fim de gerar interesse e maior adesão às ações desenvolvidas pelas equipes de saúde.

Embora se observe algumas atividades relacionadas à educação em saúde realizadas pelas equipes, se fazem necessário maiores investimentos em capacitações, além de possibilitarem condições de trabalho que oportunizem um cuidado integral e, assim, retomarem os princípios do Sistema Único de Saúde.

Em relação às atividades de promoção e prevenção é possível notar que as equipes se sentem limitadas ao seu desenvolvimento devido à existência de alta demanda a procura de atendimentos clínicos que provocam angústia e desânimo aos profissionais. Há necessidade de espaços de reflexão entre os profissionais das equipes e, a educação permanente, é uma ferramenta potente para fomentar possíveis transformações no processo de trabalho em saúde.

\section{REFERÊNCIAS}

1. Paim JS. Modelos de atenção a saúde no Brasil. In: Giovanella L, Escorel S, Lobato LVC, Noronha JC, Carvalho AI, organizadores. Políticas e sistema de saúde no Brasil. 2a ed. rev. ampl. Rio de Janeiro (RJ): Fiocruz; 2012; p. 547-73.

2. Silva Júnior AG, Alves CA. Modelos assistenciais em saúde: desafios e perspectivas. In: Morosini MVGC, Corbo ADA, organizadores. Modelos de atenção e a saúde da família. Rio de Janeiro (RJ): Fiocruz; 2007. p 27-41.

3. Sucupira AC. A importância do ensino da relação médico-paciente e das habilidades de comunicação na formação do profissional de saúde. Interface Comun Saúde Educ. 2007;11(23):624-7.

4. Carvalho G. A saúde pública no Brasil. Estud Av. 2013;27(78):7-26.

5. Marin MJS, Marchioli M, Moracvick MYAD. Fortalezas e fragilidades do atendimento nas Unidades Básicas de Saúde tradicionais e da Estratégia de Saúde da Família pela ótica dos usuários. Texto \& Contexto Enferm. 2013;22(3):780-8.

6. Brasil. Ministério da Saúde. Portaria 1.444, de 28 de dezembro de 2000. Dispõe do incentivo financeiro para reorganização da atenção a saúde bucal por meio do Programa Saúde da Família. Diário Oficial da União, Brasília (DF); 29 dez 2000; Seção 1:85.

7. Pinheiro PM, Oliveira LC. A contribuição do acolhimento e do vínculo na humanização da prática do cirurgião-dentista no Programa Saúde da Família. Interface Comun Saúde Educ. 2011;15(6):185-98.

8. Fernandes MCP, Backes VMS. Educação em saúde: perspectivas de uma equipe da Estratégia Saúde da Família sob a óptica de Paulo Freire. Rev Bras Enferm. 2010;63(4):567-73.

9. Minayo MCS. O desafio da pesquisa social. In: Minayo MCS, organizadora, Deslandes SF, Gomes R. Pesquisa social: teoria, método e criatividade. 32a ed. Petrópolis (RJ): Vozes; 2012. p. 9-29.

10. Ressel LB, Beck CLC, Gualda DMR, Hoffmann IC, Silva RM, Sehnem GD. O uso do grupo focal em pesquisa qualitativa. Texto \& Contexto Enferm. 2008;17(4):779-86.

11. Santili PGJ, Tonhom, SFR, Marin MJS. Educação em saúde: desafios na sua implementação. In: Atas do $5^{\circ}$ Congresso Ibero-Americano em Investigação Qualitativa, $1^{\circ}$ International Symposium on Qualitative Research; 12-14 jul 2016; Porto, PT [Internet]. Porto (PT): Ludomedia; 2016. [citado 29 jul 2016]. Disponível em: <http://proceedings.ciaiq.org/index. php/ciaiq2016/article/view/757/744>. Acesso em: 29 jul. 2016. 
12. Minayo MCS. Trabalho de campo: contexto de observação, interação e descoberta. In: Minayo MCS, organizadora, Deslandes SF, Gomes R. Pesquisa social: teoria, método e criatividade. 32a ed. Petrópolis (RJ): Vozes; 2012. p. 61-78

13. Fertonani HP, Pires DEP, Biff D, Anjos Scherer MD. Modelo assistencial em saúde: conceitos e desafios para a atenção básica brasileira. Ciênc Saúde Coletiva. 2015;20(6):1869-78.

14. Franco TB, Merhy EE. Programa de Saúde da Família (PSF): contradições de um programa destinado à mudança do modelo tecnoassistencial. In: Merhy EE, Magalhães Júnior HM, Rimoli J, Franco TB, Bueno WS, organizadores. O trabalho em saúde: olhando e experienciando o SUS no cotidiano São Paulo (SP): Hucitec; 2003. p. 55-124.

15. Roncalli AG. A organização da demanda em serviços públicos de saúde bucal: universalidade, eqüidade e integralidade em saúde bucal coletiva [tese]. Araçatuba (SP): Universidade Estadual Paulista; 2000. 238 p.

16. Rosolin RAM. A influência da demanda espontânia na (des)caracterização do processo de trabalho na Estratégia Saúde da Família [tese] Botucatu (SP): Universidade Estadual Paulista ; 2014. 111 p.

17. Feuerwerker L. Modelos tecnoassistenciais, gestão e organização do trabalho em saúde: nada é indiferente no processo de luta para a consolidação do SUS. Interface Comun Saúde Educ. 2005;9(18):489-506.

18. Buss PM. Uma introdução ao conceito de promoção da saúde. In: Czeresnia D, Freitas CM. Promoção da saúde: conceitos, reflexões, tendências. Rio de Janeiro (RJ): Fiocruz; 2003. p. 19-42.

19. Chiesa AM, Veríssimo M. A educação em saúde na prática do PSF. Instituto para o Desenvolvimento da Saúde; Universidade de São Paulo; Ministério da Saúde, organizadores. Manual de enfermagem. Brasília (DF): Ministério da Saúde; 2001. p. 34-42.

20. Brasil. Ministério da Saúde. Política Nacional de Promoção da Saúde. Brasília (DF): Ministério da Saúde; 2006.
21. Campos GW, Barros RB, Castro AM. Avaliação de Política Nacional de Promoção da Saúde. Ciênc Saúde Coletiva. 2004;9(3):745-9.

22. Langdon EJ, Wiik FB. Antropologia, saúde e doença: uma introdução ao conceito de cultura aplicado às ciências da saúde. Rev Latinoam Enferm. 2010;18(3):173-81.

23. Laraia RB. Cultura: um conceito antropológico. Rio de Janeiro (RJ): Zahar; 2001.

24. Oliveira ATSA, Moreira CT, Machado CA, Vasconcelos Neto JA, Machado MFAS. Crendices e práticas populares: influência na assistência de enfermagem prestada à criança no Programa Saúde da Família. Rev Bras Promoç Saúde. 2012;19(1):11-8.

25. Oliveira HM, Gonçalves MJF. Educação em saúde: uma experiência transformadora. Rev Bras Enferm. 2004;57(6):761-3.

26. Sales FMS. Ações de educação em saúde para prevenção e controle da dengue: um estudo em Icaraí, Caucaia, Ceará. Ciênc Saúde Coletiva. 2008;13(1):175-84.

27. Gomes LB, Merhy EE. A educação popular e o cuidado em saúde: um estudo a partir da obra de Eymard Mourão Vasconcelos. Interface Comun Saúde Educ. 2014;18(Supl 2):1427-40.

28. Marin MJS, Moracvick MYAD, Rodrigues LCR, Santos SC, Santana FHS, Amorim DMR. Conhecendo os motivos da não adesão às ações educativas em saúde. REME Rev Mineira Enferm. 2013;17(3):505-9.

29. Camargo-Borges C, Mishima SM. A responsabilidade relacional como ferramenta útil para a participação comunitária na atenção básica. Saúde Soc. 2009;18(1):29-41.

\section{Endereço para correspondência:}

Priscila Josepetti Santili

Av. José de Grande, 332

CEP: 17519-470 - Marília - SP - Brasil

E-mail: santilijosepetti@hotmail.com 